УДК 541.123.3

\title{
ЗАВИСИМОСТЬ ЭНЕРГИИ ГЕЛЬМГОЛЬЦА ОТ ТЕМПЕРАТУРЫ ВСПЫШКИ Н-АЛКИЛБЕНЗОЛОВ
}

\author{
(C) 2017 Ю. К. Сунцов ${ }^{1}$, Ю. Н. Сорокина ${ }^{2}$ \\ 'Воронежский государственный педагогический университет, ул. Ленина, 86, \\ 394043 Воронеж, Россия \\ 2'Воронежский институт ГПС МЧС России, ул. Краснознамённая, 231, 394052 Воронеж, Россия \\ e-mail:jsyntsov@mail.ru,sorokina-jn@mail.ru
}

Поступила в редакцию 08.11.2017

\begin{abstract}
Аннотация. Эбулиометрическим методом при различных давлениях измерены температуры кипения четырёх веществ гомологического ряда н-алкилбензолов. На основе опытных данных с использованием стандарта идеального газа рассчитаны значения внутренней энергии, энтропии и энергии Гельмгольца веществ гомологического ряда н-алкилбензолов. Установлено, что значения термодинамических функций веществ аддитивно зависят от молярной массы н-алкилбензола в гомологическом ряду. Анализом литературных данных обнаружена также аддитивная зависимость температур вспышки веществ от молярной массы н-алкилбензолов. Установлено, что значения энергии Гельмгольца линейно зависят от температуры вспышки н-алкилбензолов в гомологическом ряду. Приведены необходимые для расчётов свойств веществ уравнения.
\end{abstract}

Ключевые слова: равновесие жидкость-пар, энергия Гельмгольца, внутренняя энергия, энтропия; температура вспышки, уравнение состояния.

\section{ВВЕДЕНИЕ}

Для технологических процессов производства, хранения и транспортирования н-алкилбензолов необходимы данные о термодинамических свойствах и показателях пожаровзрывоопасности веществ. К числу важнейших показателей пожаровзрывоопасности относятся температуры вспышки и воспламенения огнеопасных жидкостей, которые можно рассчитать на основе исследований фазовых равновесий жидкость-пар [1]. Известно, что исследование фазовых равновесий связано с большими экспериментальными трудностями [2]. Поэтому разработка метода прогнозирования термодинамических свойств и показателей пожаровзрывоопасности веществ, исходя из минимального количества экспериментальных данных, является актуальной задачей. Решение этой задачи связано с установлением взаимосвязи между молекулярными характеристиками и термодинамическими свойствами веществ в гомологических рядах.

Ранее была установлена функциональная взаимосвязь температуры вспышки и энергии Гельмгольца с молярной массой веществ гомологических рядов: н-алкилэтаноатов, н-алкилпропаноатов, н-спиртов, н-кетонов, н-алкиламинов [3-5]. В данной работе предпринята попытка установления по- добных аналитических зависимостей для веществ гомологического ряда н-алкилбензолов.

\section{ЭКСПЕРИМЕНТАЛЬНАЯ ЧАСТЬ}

В качестве объекта исследования выбраны вещества: бензол, метилбензол, этилбензол, н-пропилбензол, н-бутилбензол. Константы очищенных веществ удовлетворительно совпадали с литературными данными [6]. Температуры кипения растворов $(T)$ измерялись эбулиометрическим методом при пониженных давлениях ( $p$ ) платиновым термометром сопротивления с точностью $\pm 0.05 \mathrm{~K}$. Давление насыщенного пара растворов $(P)$ измерялось ртутным манометром, с использованием катетометра В-630, с точностью \pm 6.66 Па. Постоянство давления в эбулиометрах поддерживалось изодромным регулятором с отрицательной обратной связью с точностью \pm 6.66 Па. Плотность чистых веществ и их растворов измерялась с помощью пикнометров Оствальда объёмом 50, $100 \mathrm{~cm}^{3}$ при температурах 298.15, 318.15, 338.15 К. Детальное описание экспериментальных установок и методик эксперимента приведено в [7]. Значения энергии Гиббса, энтальпии и энтропии налкилбензолов, рассчитанные с использованием метода Льюиса, не удалось связать уравнением с молярной массой (структурой) веществ. Основной не- 
достаток расчета по методу Льюиса заключается в том, что получаемые значения термодинамических функций оказываются малочувствительными к межмолекулярному взаимодействию (МMB) в жидкости. Для расчётов вкладов ММВ в термодинамические функции использовали идеальный газ, взятый при температуре $(T)$ и объёме $(V)$ реальной жидкости. В случае перехода моля вещества из состояния идеального газа в жидкое состояние (с межмолекулярным взаимодействием) получили [7]:

$$
\begin{gathered}
\hat{F}=R T \ln \frac{R T}{P V}-R T+P V ; \\
\hat{U}=H-R T \ln \frac{R T}{P V} ; \\
\hat{S}=H-R T \ln \frac{R T}{P V},
\end{gathered}
$$

где $\hat{F}$ - энергия Гельмгольца; $R$ - универсальная газовая постоянная; $T$ - температура, К; $P, V$ - давление пара и мольный объем жидкости; $\hat{U}$ - внутренняя энергия; $H$ - мольная энтальпия испарения жидкости; $\hat{S}$ - энтропия. Значения энтальпии испарения $H$ в уравнениях (2) и (3) рассчитывались по уравнению Клаузиуса-Клайперона с использованием зависимости давления насыщенного пара от температуры веществ [2].

\section{РЕЗУЛЬТАТЫ И ИХ ОБСУЖДЕНИЕ}

На основе экспериментальных и литературных данных [6] по уравнениям (1)-(3) рассчитаны значения $\hat{F}, \hat{U}$ и $\hat{S}$ жидких н-алкилбензолов. Анализ результатов расчетов показывает, что значения $\hat{F}, \hat{U}$ и $\hat{S}$ н-алкилбензолов аддитивно зависят от их молярной массы в гомологическом ряду и могут быть описаны уравнениями $(T=353 \mathrm{~K})$ :

$$
\begin{aligned}
& \hat{F}=151.6 M+2067, R^{2}=0.9993 \\
& \hat{U}=291.9 M+4545, R^{2}=0.9991 \\
& T \hat{S}=140.3 M+2478, R^{2}=0.9947
\end{aligned}
$$

где $M$ - молярная масса вещества; $\hat{F}, T \hat{S}$ и $\hat{U}$ - в Дж /моль. Уравнения (4)-(6) описывают термодинамические свойства жидких н-алкилбензолов с точностью \pm 50 Дж/моль и могут быть использованы для прогнозирования значений $\hat{F}, \hat{U}, T \hat{S}$ неисследованных веществ гомологического ряда н-алкилбензолов.

Аддитивную зависимость значений термодинамических функций от молярной массы вещества в гомологическом ряду можно объяснить подобием структурообразования жидких н-алкилбензо- лов [8]. Поскольку энергия Гельмгольца $\hat{F}$ наиболее точно рассчитывается по экспериментальным данным, представлялось целесообразным установить связь этой функции с мольным объемом $(V)$ и давлением $(P)$ насыщенного пара веществ гомологического ряда. Корреляционным анализом установлено, что величины $\ln P, V$ линейно зависят от значений $\hat{F}$ веществ в гомологическом ряду и могут быть описаны уравнениями вида:

$$
\begin{gathered}
\hat{F}=-2472 \ln P+42288, R^{2}=0.9998 ; \\
\hat{F}=122.78 V+2107.9, R^{2}=0.9992 .
\end{gathered}
$$

Возрастание величины $\hat{F}$ ММВ затрудняет переход молекул веществ в паровую фазу и уменьшает по экспоненциальной зависимости давление насыщенного пара жидкости.

Температура вспышки, принятая за основу классификации жидкостей по степени их пожаровзрывоопасности, является одним из важнейших показателей пожарной опасности. Анализом литературных данных [9] установлено, что температура вспышки н-алкилбензолов аддитивно возрастает с увеличением молярной массы (числа групп - $\mathrm{CH}_{2}-$ в молекуле) вещества в гомологическом ряду:

$$
T_{\text {всІ }}=1.2262 M+165.97 ; R^{2}=0.9968,
$$

где $T_{\text {всп }}$ - температура вспышки, К.

С учётом установленных закономерностей изменения значений термодинамических функций и температуры вспышки от молярной массы н-алкилбензола (уравнения (4)-(6), (9)) представлялось целесообразным установить взаимосвязь энергии Гельмгольца с температурой вспышки вещества в гомологическом ряду. С этой целью значения энергии Гельмгольца $\hat{F}$ были пересчитаны для температур вспышки веществ в гомологическом ряду. Оказалось, что энергия Гельмгольца при температуре вспышки веществ также аддитивно возрастает с увеличением молярной массы вещества (числа групп $-\mathrm{CH}_{2}-$ в молекуле) в гомологическом ряду н-алкилбензолов:

$$
\hat{F}_{\text {всп }}=84.487 M+12619, R^{2}=0.9951 .
$$

С учётом тенденции изменения температуры вспышки и энергии Гельмгольца (рассчитанной при температуре вспышки) от молярной массы вещества в гомологическом ряду представлялось целесообразным установить их взаимосвязь (рис. 1).

Корреляционным анализом с использованием программы TableCurve 3D v4.0 для н-алкилбензолов получено уравнение:

$$
\hat{F}=68.428 T_{\text {всп }}+1316.6, R^{2}=0.9846 .
$$




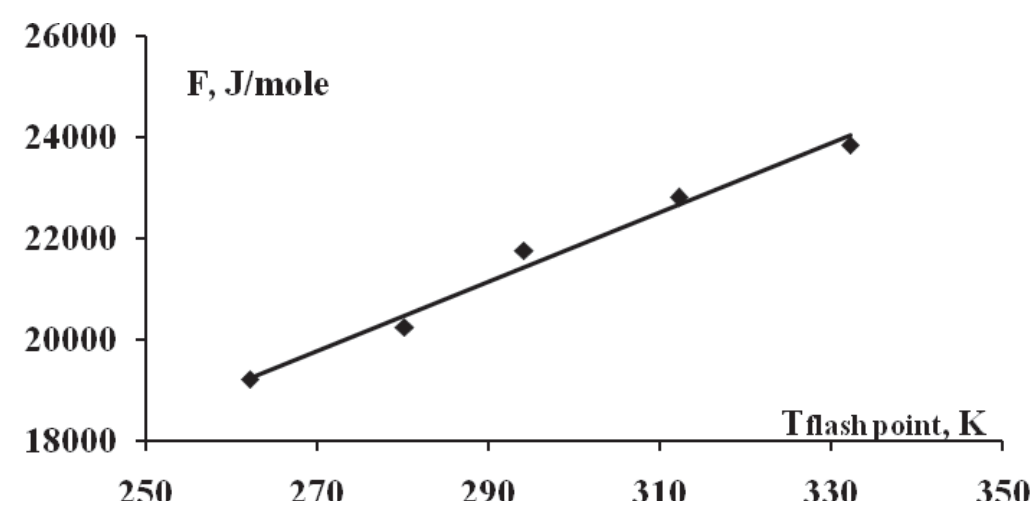

Рис. 1. Зависимость энергии Гельмгольца от температуры вспышки в гомологическом ряду н-алкилбензолов [Fig. 1. Dependence of the Helmholtz energy on the flash temperature in the homologous series of n-alkylbenzenes]

Уравнение (11) с необходимой для технических целей точностью позволяет рассчитывать температуры вспышки н-алкилбензолов, используя свойства двух веществ гомологического ряда. Точность вычислений зависит только от точности экспериментальных данных для этих веществ. Ранее подобные закономерности были выявлены для веществ гомологических рядов н-алкилэтаноатов, нспиртов, кетонов и н-алкиламинов [3-5]. По мнению авторов, установленные закономерности могут быть применены к веществам других гомологических рядов.

\section{ВЫВОДЫ}

1. Значения энергии Гельмгольца $\hat{F}$, внутренней энергии $\hat{U}$ и энтропии $\hat{S}$ аддитивно зависят от молярной массы веществ (числа групп $-\mathrm{CH}_{2}-$ в молекуле) в гомологическом ряду н-алкилбензолов и описаны уравнениями (4-6) с точностью \pm 50 Дж/моль.

2. Показано, что межмолекулярное взаимодействие в жидкости необходимо оценивать по значениям термодинамических функций, рассчитанных по стандарту идеального газа, взятого при тех же температурах и объеме, что и испытуемая жидкость.

3. Установлено, что температура вспышки н-алкилбензолов аддитивно возрастает с увеличением молярной массы (числа групп $-\mathrm{CH}_{2}-$ в молекуле) вещества в гомологическом ряду (уравнение (9)).

4. Возрастание значений температуры вспышки связано с аддитивным увеличением значений энергии Гельмгольца в гомологическом ряду н-алкилбензолов (уравнение (11)).
5. Предложена методика, позволяющая прогнозировать термодинамические свойства и температуры вспышки н-алкилбензолов, опираясь на свойства двух веществ гомологического ряда.

6. Установленные в работе соотношения позволяют на термодинамической основе совершенствовать систему ГОСТ, относящихся к «Пожаровзрывоопасности веществ и материалов. Номенклатуре показателей и методов их определения».

\section{СПИСОК ЛИТЕРАТУРЫ}

1. Алексеев С. Г., Смирнов В. В., Барбин Н. М. // Пожаровзрывобезопасность, 2012, т. 21, № 10, с. 21-35.

2. Морачевский А. Г., Смирнова Н. А., Пиотровская Е. М. и др. Термодинамика равновесия жидкостьnap. Ленинград, Химия, 1989, 344 с.

3. Сунцов Ю. К., Сорокина Ю. Н., Чуйков А. М., Горюнов В. А. // Пожаровзрывобезопасность, 2016, т. 25 , № 3 , c. 27-33.

4. Сунцов Ю. К., Сорокина Ю. Н., Чуйков А. М. // Пожаровзрывобезопасность, 2017, т. 26, № 4, с. 2128.

5. Чуйков А. М., Сунцов Ю. К., Сорокина Ю. Н., Лукьяненко В. И., Шуткин А. Н. // Вестник Воронежского государственного технического университета, 2017, т. 13, № 3, c. 45-49.

6. Stephenson R. M., Malanowski S. Handbook of the Thermodynamics of Organic Compounds. New York, Elsevier, 1987, $552 \mathrm{p}$.

7. Suntsov Yu. K. Journal of Chemistry and Chemical Engineering, 2014, vol. 8, № 3, pp. 306-314.

8. Скрышевский А. Ф. Структурный анализ жидкостей. М.: Высшая школа, 1971, 256 с.

9. Корольченко А. Я., Корольченко Д. А. Пожаровзрывоопасность веществ и материалов и средства их тушения. М.: Пожнаука, 2004, ч. I., 713 с.; ч. II., 774 с. 


\title{
DEPENDENCE OF THE HELMHOLZ ENERGY FROM THE TEMPERATURE OF FLASH N-ALKYL BENZENS
}

\author{
(C) 2017 Yu. K. Suntsov ${ }^{1}$, Yu. N. Sorokina ${ }^{2}$ \\ ${ }^{1}$ Voronezh State Pedagogical University, 86 Lenin str., 394043 Voronezh, Russia \\ ${ }^{2}$ Voronezh Institute of State Firefighting Service of Emercom of Russia, 231 Krasnoznamennaya str., \\ 394052 Voronezh, Russia \\ e-mail: jsyntsov@mail.ru,sorokina-jn@mail.ru
}

Received 08.11.2017

\begin{abstract}
The number of organic compounds has exceeded 40 million and further increases by 300 thousand each year. To ensure the fire safety and the accuracy of the production process design, as well as the safe storage and transportation of materials, it is necessary to determine the level of fire and explosion hazard of various substances. It is therefore extremely important to develop a method for determining the fire hazard indicators and thermodynamic properties of substances, based on the minimum amount of experimental data. To solve this problem we consider it necessary to determine the dependencies between the molecular characteristics and the thermodynamic properties of homologous substances. The focus of the present research is on the homologous series of n-alkyl benzenes. The analysis determined that the thermodynamic functions of substances additively depend on the molar weight of n-alkyl benzenes in the homologous series. Similar dependence was observed for the flash point of $n$-alkyl benzenes. Taking into account the fact that the flash point values and the Helmholtz energy tend to change depending on the molar weight of the substances in the homologous series, it seems practical to establish their interrelation. The corresponding equations were derived. Similar dependencies were previously observed for the homologous series of n-alkyletanoats, aliphatic ketones, n-alkylamines, and alcohols. The established regularities and proposed equations allow us to forecast the properties of homologous series of substances with sufficient accuracy.
\end{abstract}

Keywords: saturated vapor pressure; molar volume, internal energy, entropy and Helmholtz energy, the flash point, correlation equations.

\section{REFERENCES}

1. Alekseev S. G., Smirnov V. V., Barbin N. M. Fire and Explosion Safety, 2012, vol. 21, no. 10, pp. 21-35.

2. Morachevskij A. G., Smirnova N.A., Piotrovskaja E. M. Thermodynamics of the Equilibrium of Liquid-Vapor. Leningrad, Chemistry Publ., 1989, 344 p. (in Russian)

3. Suntcov Ju. K., Sorokina Ju. N., Chujkov A. M., Gorjunov V. A. Fire and Explosion Safety, 2016, vol. 25, no. 3, pp. 27-33. DOI: 10.18322/PVB.2016.25.03.27-33

4. Suntsov Yu. K., Sorokina Yu. N., Chuykov A. M. Fire and Explosion Safety, 2017, vol. 26, no. 4, pp. 21-28.

5. Chuikov A. M., Suntsov Yu. K., Sorokina Yu. N., Lukyanenko V. I., Shutkin A. N. The Bulletin of Voronezh
State Technical University, 2017, vol. 13, no. 3, pp. 45-49. (in Russian)

6. Stephenson R. M., Malanowski S. Handbook of the Thermodynamics of Organic Compounds. New York, Elsevier, 1987, 552 p. DOI: 10.1007/978-94-009-3173-2

7. Suntsov Yu. K. Journal of Chemistry and Chemical Engineering, 2014, vol. 8, no. 3, pp. 306-314. DOI: 10.17265/1934-7375/2014.03.013

8. Skryshevsky A. F. Structural Analysis of Liquids. Moscow, Higher School Publ., 1971, 256 p. (in Russian)

9. Korolchenko A. Ya., Korolchenko D. A. Fire and Explosion Hazard of Substances and Materials and Their Means of Extinguishing. Moscow, Poznauka Publ., 2004, Pt. I., 713 p.; Pt. II., 774 p. (in Russian)
Сунцеов Юрий Константинович - д. х. н., профессор, заведующий кафедрой безопасности жизнедеятельности, Воронежский государственный педагогический университет; тел.: +7(950) 7618967, e-mail: jsyntsov@mail.ru

Сорокина Юлия Николаевна - к. т. н., доцент, доцент кафедры химии и процессов горения, Воронежский институт ГПС МЧС России; тел.: +7(906) 5858001; e-mail: sorokina-jn@mail.ru
Suntsov Yuri K. - Dr. Sci. (Chem.), Professor, Head of the Department of Life Safety, Voronezh State Pedagogical University; ph.: +7(950) 7618967, e-mail: jsyntsov@mail.ru

Sorokina Yuliya N. - Cand. Sci. (Eng.), Docent, Associate Professor of the Chemistry and Combustion Department, Voronezh Institute of State Firefighting Service of Emercom of Russia; ph.: +7(906) 5858001; e-mail: sorokina-jn@mail.ru 